\title{
Crustal deformation associated with the 1998 seismo-volcanic crisis of Iwate Volcano, Northeastern Japan, as observed by a dense GPS network
}

\author{
Satoshi Miura, Sadato Ueki, Toshiya Sato, Kenji Tachibana, and Hiroyuki Hamaguchi \\ Graduate School of Science, Tohoku University, Sendai 980-8578, Japan
}

(Received January 4, 2000; Revised August 28, 2000; Accepted September 4, 2000)

\begin{abstract}
Mt. Iwate $(2,038 \mathrm{~m})$ is an active volcano located in northeastern Japan. Unrest of the volcano started in September, 1995 with intermediate-depth tremors. The shallow seismicity gradually became active in February, 1998, accompanying the notable crustal deformation observed by a dense GPS network. The pattern of the horizontal displacements is characterized by radially directing outward from the volcano. We estimated the source position by inversion analyses for every two-months period, assuming two models; a point pressure source (Mogi model) and a tensile fault. The comparison of AIC's for the two models indicates that the latter is proper from February to April, while the former is preferable afterward. The tensile fault was located at about $5 \mathrm{~km} \mathrm{WSW}$ of the summit and $3 \mathrm{~km}$ in depth, then a Mogi source was estimated at the western neighbor of the tensile fault in the successive period and moved westward as far as $10 \mathrm{~km} \mathrm{~W}$ of the summit with shallowing its depth. It should be noted that the seismic area also expanded westward in the same period. This synchronicity suggests that the both phenomena were caused by a movement of magma from the deeper part beneath the summit to the western shallower part.
\end{abstract}

\section{Introduction}

Mt. Iwate $(2,038 \mathrm{~m})$ is one of the most active volcano in northeastern Honshu, Japan and having histories of magmatic eruptions in 1686 and 1732. Before 1994, seismicity around the volcano was very low, say, twice a year in average, as shown in Fig. 1. Unrest of Iwate volcano, however, started in September, 1995 with intermediate-depth tremor and since then activity of tremors and microearthquakes has slightly increased. Since June, 1996, high-frequency events including relatively large earthquakes with $M>2.0$ have occurred in the shallower part beneath the summit of the volcano (Ueki et al., 1996). The shallow seismicity in the west of the summit gradually became active since February, 1998, and reached a peak at the end of April (Tanaka et al., 1999) as shown in Fig. 2. The active seismicity including 25 felt shocks of $M>2.0$ continued till the middle of August. Increase in fumarolic activity was also reported during the same period. Associated with the seismo-volcanic crisis, the notable crustal deformation was observed by the dense GPS network established by Tohoku University (Ueki et al., 1999), strain and tilt measurements (Sato and Hamaguchi, 1999) and leveling surveys (Kimata et al., 1999). In this study we first show characteristics of the displacement observed by GPS. Next, we apply a geodetic inversion method to estimate source models for the observed deformation.

\section{Observation and Data}

The GPS network around Iwate Volcano is shown in Fig. 3. Closed and open circles denote the continuous and temporary GPS stations, respectively, operated by Tohoku University.

Copy right(C) The Society of Geomagnetism and Earth, Planetary and Space Sciences (SGEPSS); The Seismological Society of Japan; The Volcanological Society of Japan; The Geodetic Society of Japan; The Japanese Society for Planetary Sciences.
This may be one of the densest networks of GPS continuous stations in Japan. Only one station, IWT was in operation when the unrest of the volcano initiated in September, 1995. Soon after that, two stations, ANS and YKBC, were added in October, 1995. In 1996, continuous observation was started at two more stations, PUTA and IKG. Other 6 stations have been established since March, 1998 when the shallower seismicity around the west of the summit were activated. We deployed Ashtech's dual-frequency receivers at all stations. Data are transferred to our university using wire telephones from most of the stations, cellular telephones from INKR and IKGS, or radio modems from HDTR. The telemetering system using radio modem was newly designed for stations where wire and cellular telephones are not available such as the summit area. INKR and HDTR are so far from residential areas that these stations are powered by solar batteries. Carrier phase data are sampled every minute at all stations and analyzed by using GAMIT GPS software with IGS precise ephemerides to produce daily solutions. 8 solid squares in Fig. 3 indicate the continuous GPS sites of the nationwide GPS array (GEONET) of Geographical Survey Institute (GSI) of Japan (Miyazaki et al., 1997). GSI provides SINEX files including all stations in Japan derived from their routine analysis. We utilize them to investigate surface deformation more in detail and to constrain results from inversion analyses for estimation of source models shown in later. As a result, data from 13 to 19 continuous stations, depending on the period, are used in this study.

\section{Characteristics of Crustal Deformation from February to August, 1998}

Figure 4 shows time-series of baseline vector-components (NS, EW, and UD) at PUTA and IKG, and lengths for each 


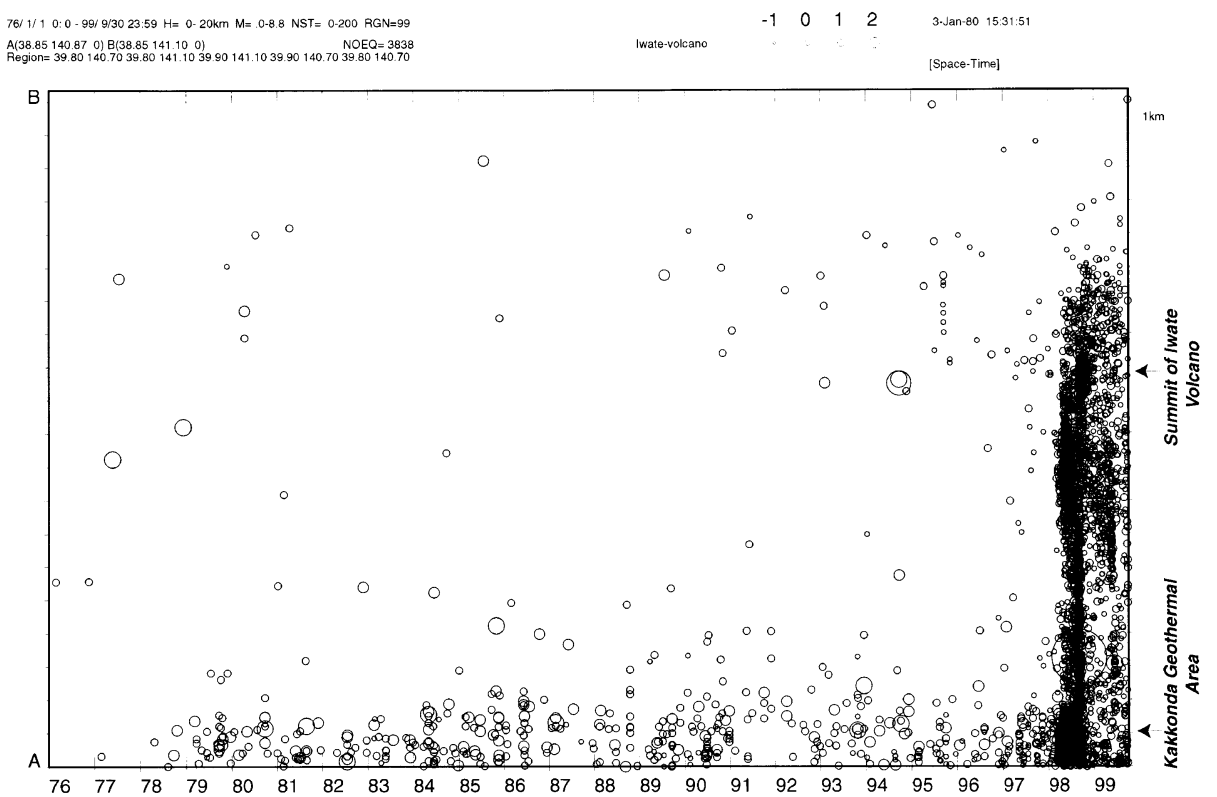

Fig. 1. Space-time plot of earthquakes occurred in the area of $10 \mathrm{~km}$ by $20 \mathrm{~km}$ including Iwate volcano since 1976 . All events determined by the seismic network of Tohoku University.

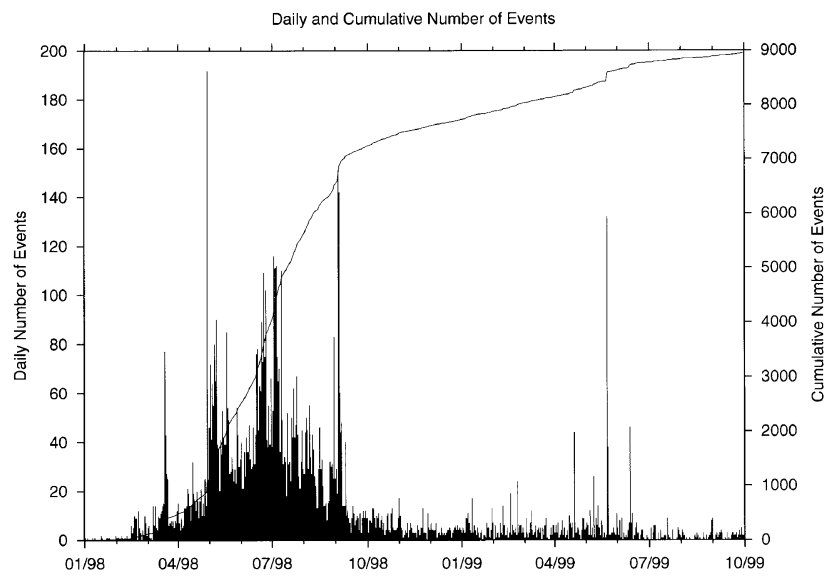

Fig. 2. Daily and cumulative number of earthquakes with amplitudes greater than 30 micro-kine counted at Matsukawa seismological station, about $7 \mathrm{~km}$ NW from the summit of Iwate volcano.

baseline with reference to Akita located at about $80 \mathrm{~km}$ west of the volcano. PUTA and IKG are located at northern and southern foots of the volcano, respectively. During the period from February to August, we observed significant deformations amounting to about $30-40 \mathrm{~mm}$ in horizontal components and $20 \mathrm{~mm}$ uplift in vertical one, for AKT-IKG baseline as an example. The step-like changes at IKG in the beginning of September were the coseismic displacement due to the M6.1 earthquake (Umino et al., 1998) occurred $10 \mathrm{~km}$ SW of the summit. After the earthquake, the significant deformation before the event almost vanished though minor displacements less than about $10 \mathrm{~mm} /$ year have continued. The deformation prior to the earthquake was observed commonly at most of the stations in the network, though the amount and direction of the displacements is different from site to site. We then conclude that the observed displace-

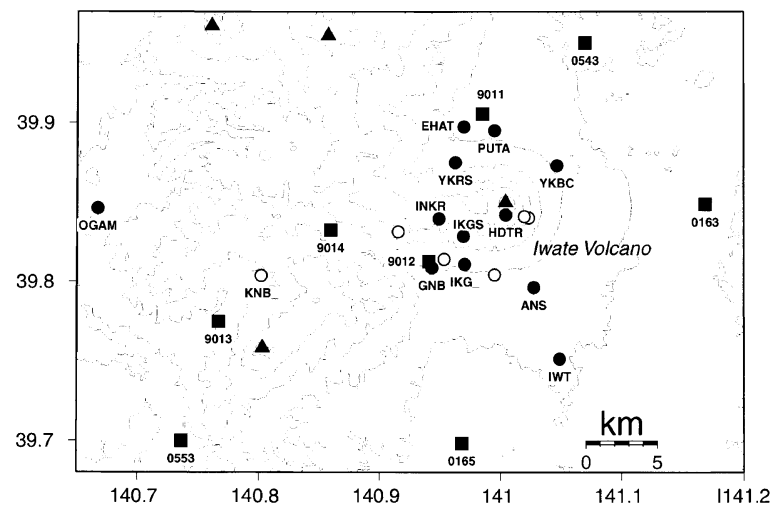

Fig. 3. Map showing GPS network around Iwate volcano. Solid and open circles denote continuous and campaign-style observation stations, respectively. Solid squares indicate continuous stations of Geographical Survey Institute of Japan.

ments from February to August was related to the seismic and volcanic activity of Mt. Iwate. Next, we investigate the temporal change in the pattern of the horizontal displacements. Time-series data of each baseline are smoothed using the digital low-pass filter devised by Saito (1978) with a cutoff period of 50 days, and displacement vectors at each station are then calculated for every two months period with shifting one month. Red arrows in Fig. 5 demonstrate the results. Solid circles indicate relocated hypocenters by Tanaka et al. (1999). Characteristics of the horizontal deformations from February to August are summarized as follows: 1) Displacement vectors approximately show the radial pattern directing outward from the western part of the volcano. 2) Displacement rates increased from February to July, especially in EW components. These observed phenomena suggest the existence of pressure sources beneath the volcanic region and its 

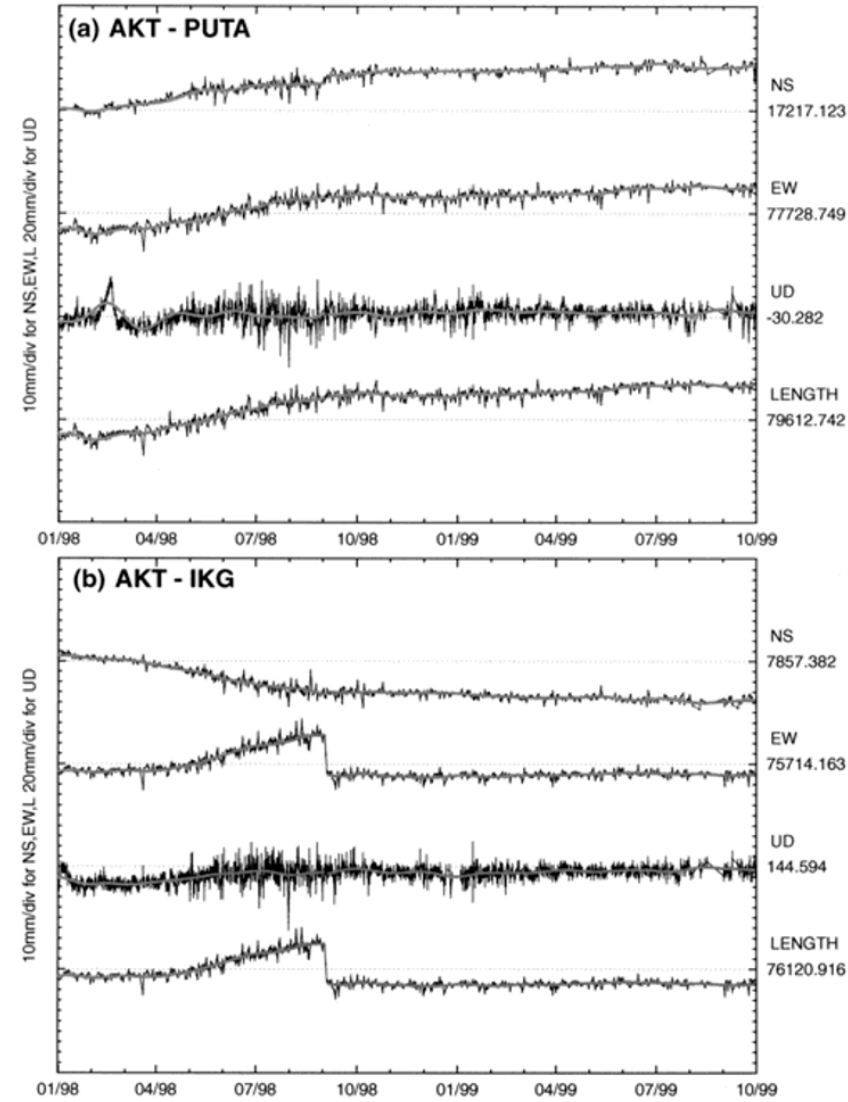

Fig. 4. Time-series of NS, EW, and UD components and length of baseline vectors from January, 1998 to September, 1999 with reference to AKT located at $80 \mathrm{~km}$ west from Iwate volcano. Solid and gray lines indicate daily solutions and smoothed ones by a digital high-cut filter with a cut-off period of 50 days, respectively. (a) AKT-PUTA and (b) AKT-IKG.

variation in location and intensity. We try to propose source models to explain the observed deformation using a geodetic inversion in the next section.

\section{Source Models for the Volcanic Deformation}

Matsu'ura and Hasegawa (1987) obtained an algorithm to find the maximum likelihood estimates for nonlinear inverse problems constrained by prior information of model parameters. Sagiya (personal communication) coded a FORTRAN program, FLTINV, to solve geodetic inversion problems based on their algorithm and Green functions of displacement fields due to a rectangular fault in a half space devised by Okada (1992). We slightly modified the original codes to deal with a point pressure source (Mogi, 1958). We at first assume a point pressure source (Mogi model) and invert the observed surface deformation from February to August. Locations and intensities of the source for each period are identified as yellow circles in Fig. 5. Displacements are calculated at each station from the estimated model parameters and shown by the blue arrows in the same figure. Unfortunately, the GPS stations are unevenly distributed in the eastern part of the estimated sources, however, the agreement between the observations and model calculation is satisfactory. It is clear that the intensity of the source gradually increased from February to July and the source migrated westward about $6 \mathrm{~km}$ in distance. It should be noted that the
Table 1. Comparison of RMS and AIC derived from inversion results.

\begin{tabular}{ccccc}
\hline Period & \multicolumn{2}{c}{ Mogi } & \multicolumn{2}{c}{ Tensile } \\
& RMS (mm) & AIC & RMS (mm) & AIC \\
\hline FEB-MAR & 2.8 & 25.55 & 2.6 & 24.47 \\
MAR-APR & 2.8 & 25.94 & 1.5 & 15.12 \\
APR-MAY & 3.3 & 31.48 & 3.2 & 32.34 \\
MAY-JUN & 2.4 & 22.37 & 2.8 & 29.56 \\
JUN-JUL & 3.2 & 39.56 & 4.2 & 66.01 \\
JUL-AUG & 4.1 & 61.84 & 4.5 & 77.21 \\
\hline
\end{tabular}

focal area of the shallow earthquakes shown as the closed circles in the same figure also expands westward (Tanaka et al., 1999) and the pressure source is located near to the western end of the seismic area for each period.

An alternative source model to interpret volcanic deformation is a dike intrusion. We then assume a rectangular tensile fault for inversion analyses. To lower the number of parameters the dimension and the dip angle of the model fault are fixed as $2 \mathrm{~km}$ by $2 \mathrm{~km}$ and 90 degree, respectively. Results are shown in Fig. 6. Table 1 lists the weighted root mean squares (WRMS) and AIC (Akaike Information Criteria). WRMS's and AIC's of the tensile fault model are small until May, and April, respectively, though the differences are not very large. After that period both indices are clearly small in Mogi models. We then can conclude that the observed deformation was due to the dike intrusion in the beginning of the 1998 activity until April or May and the dominant source changes its nature from the dike to the isotropic pressure source and migrates westward. Figure 7 summarizes the source locations. Note that the tensile fault was located beneath the focal region of the shallow earthquake and the pressure source moves around deeper border of the focal region. The synchronicity of the crustal deformation and seismic activity suggests that the both phenomena were caused by a movement of material intruded from depths beneath the summit to the western shallow part.

Ueki (2000) recently tried to identify the intruded material from magma, water, or steam. Using a simple diffusion model, he examined the post-intrusion process constrained by the source model of the surface deformation and the fumarolic activity to conclude that magma is the most possible material.

\section{Coseismic Deformation Caused by the M6.1 Event Occurred in September 3, 1998}

Significant coseismic deformations were also observed associated with the M6.1 earthquake of September 3, 1998, which took place at about $10 \mathrm{~km} \mathrm{SW}$ of the summit. We estimated the fault parameters assuming a homogeneous dislocation on a rectangular fault. The observed displacements at each station are shown in Fig. 8 together with the calculated displacement from the model. There are some discrepancies between the observation and model calculation. These may 

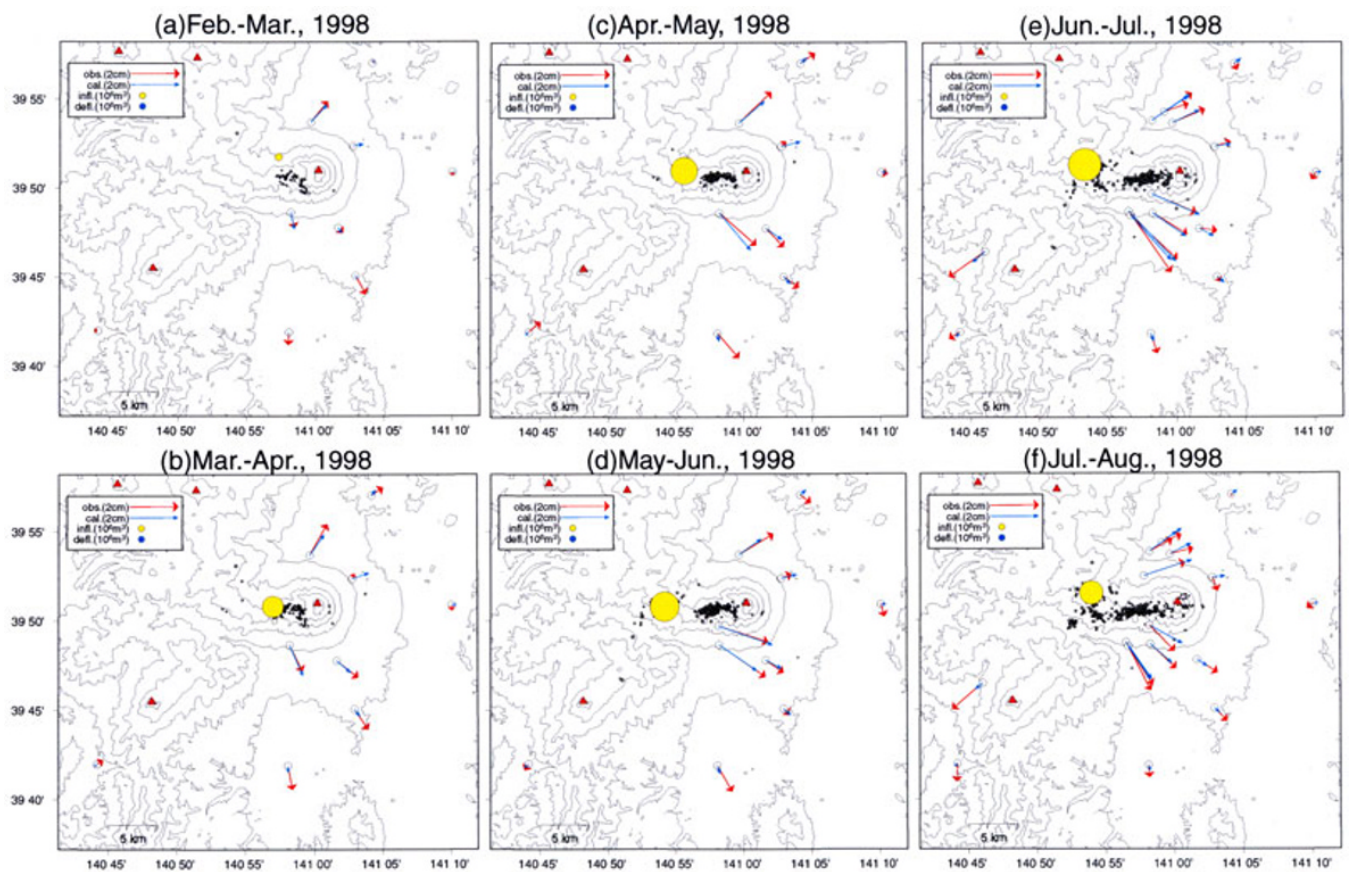

(d)May-Jun., 1998

(f)Jul.-Aug., 1998
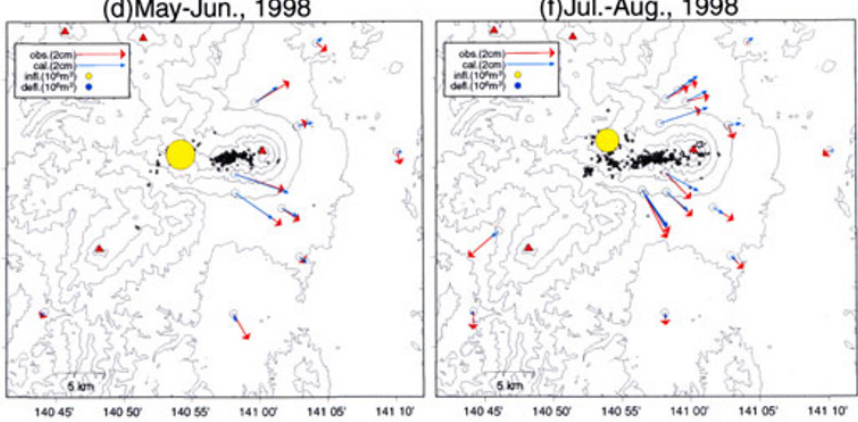

Fig. 5. Distribution of horizontal displacements for every two month from February to August, 1998. Red and blue arrows indicate observed and calculated displacements assuming a point pressure source (Mogi model), respectively. Locations of the sources are indicated by yellow circles for Mogi models.
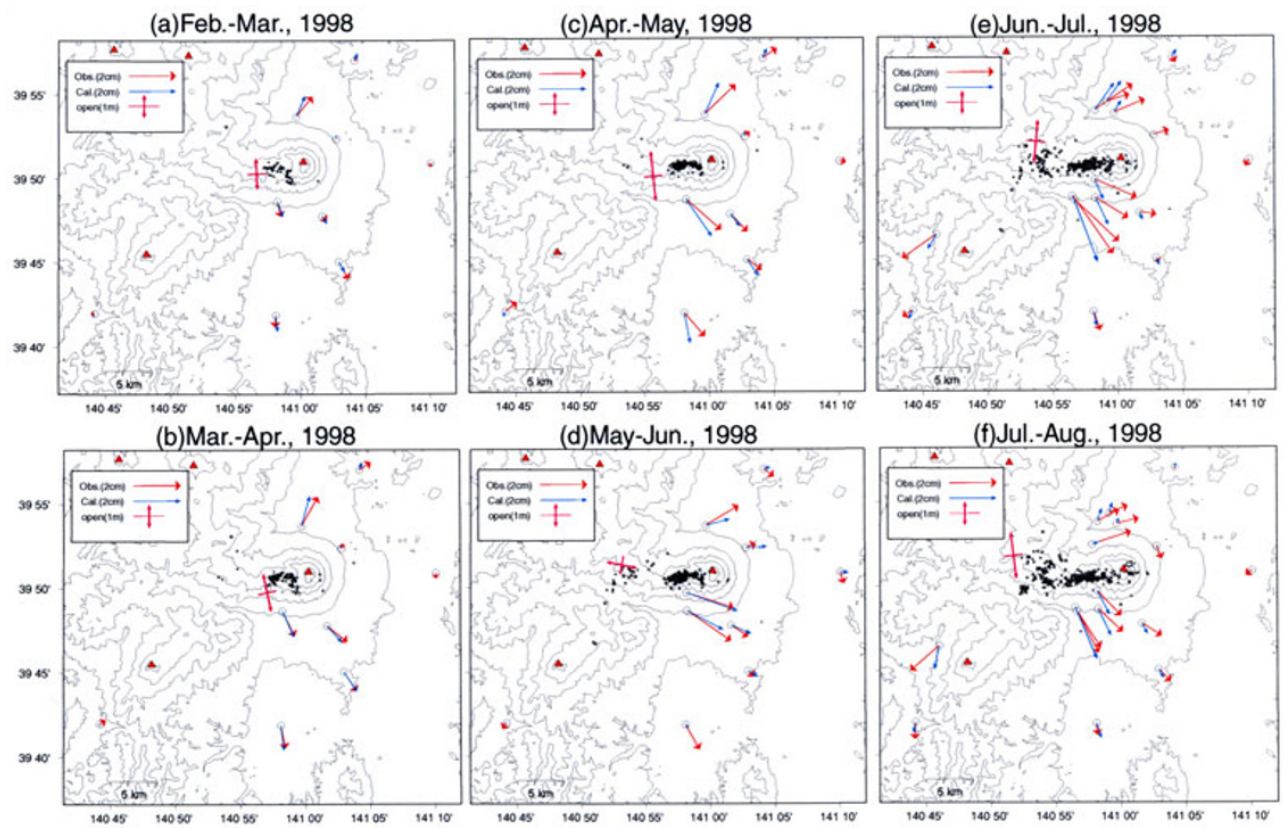

Fig. 6. Same as Fig. 5 but assuming a tensile fault. Locations of the tensile faults are indicated by violet lines with arrows.

be due to antenna instability because of the strong ground motion or the simplicity of the fault model. In spite of these minor disagreements, the fault parameters obtained in this study is consistent with the focal mechanisms derived from the seismological analyses as shown in Table 2.

The earthquake caused surface rupture traced about $800 \mathrm{~m}$ along strike, dipping to the west and northwest, and displaced reversely amounting $0.25-0.32 \mathrm{~m}$ in vertical (Koshiya et al.,
1998).

The surface deformations around Iwate volcano decreased in rate after the earthquake as shown in Fig. 4. No major systematic deformation suggesting an inflation or deflation source are obtained after the earthquake except for the period of May and June, 1999, when the shallow seismicity was slightly increased temporally (see Fig. 2). 
Table 2. Comparison of fault parameters for the M6.1 earthquake occurred on September 3, 1998.

\begin{tabular}{|c|c|c|c|c|c|c|c|c|}
\hline Data/Method & $\begin{array}{l}\text { Length } \\
(\mathrm{km})\end{array}$ & $\begin{array}{l}\text { Width } \\
(\mathrm{km})\end{array}$ & $\begin{array}{l}\text { Strike } \\
\text { (deg.) }\end{array}$ & $\begin{array}{c}\text { Dip } \\
\text { (deg.) }\end{array}$ & $\begin{array}{l}\text { Rake } \\
\text { (deg.) }\end{array}$ & $\begin{array}{l}\text { Slip } \\
(\mathrm{m})\end{array}$ & $\begin{array}{c}M_{0} \\
\left(10^{17} \mathrm{Nm}\right)\end{array}$ & $M_{W}$ \\
\hline This study & 6 & 10 & 203 & 35 & 117 & 0.37 & 7.2 & 5.8 \\
\hline $\mathrm{P}$ polarity ${ }^{1}$ & $\sim 10$ & $\sim 10$ & 233 & 53 & 149 & & & \\
\hline $\mathrm{MT}(\mathrm{NIED})^{2}$ & & & 217 & 44 & 118 & & 7.5 & 5.9 \\
\hline CMT (Harvard) ${ }^{3}$ & & & 236 & 61 & 131 & & 7.2 & 5.8 \\
\hline
\end{tabular}

${ }^{1}$ after Umino et al. (1998).

${ }^{2}$ http://argent.geo.bosai.go.jp/freesia/automt.html.

${ }^{3}$ distributed by e-mail.

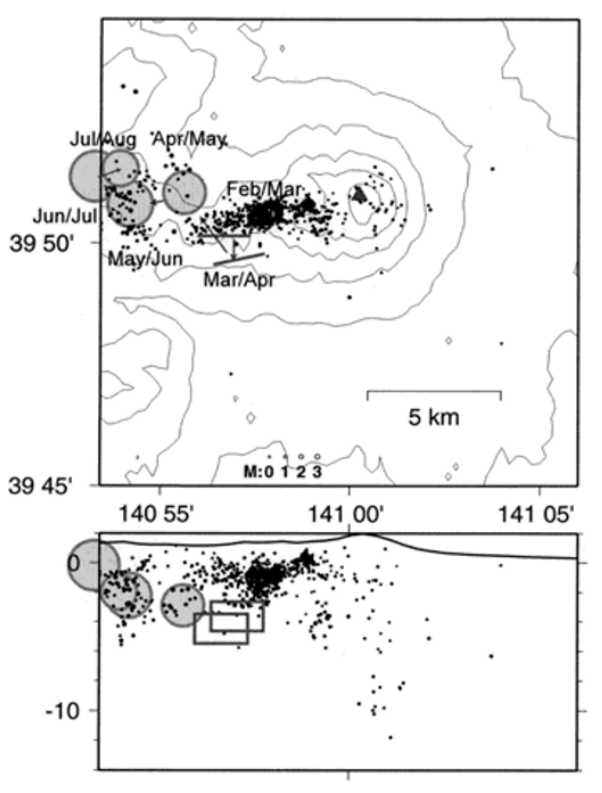

Fig. 7. Location of pressure sources projected onto the horizontal and vertical section of hypocenteral distribution. Solid lines, Gray circles, and black dots indicate locations of tensile faults, pressure sources, and hypocenters (Tanaka et al., 1999), respectively.

\section{Discussion and Conclusion}

GSI (1999), and NASDA and Nagoya University (1999) revealed the noticeable crustal deformation due to the volcanic activity of Mt. Iwate and the M6.1 earthquake using interferometric synthetic aperture radar (InSAR). GSI (1999) presented a source model consistent with this study though the inflation source is located more deep.

Nishimura et al. (2000) found more than 800 of the very long-period seismic events with a dominant period of $10 \mathrm{sec}$ onds and duration of 30-60 seconds in 1998. They analyzed the broadband seismograms in detail to reveal that the events are generated by transportation and movement of magma or water at the source region elongating in the east-west direction for about $4 \mathrm{~km}$ at a depth of $2 \mathrm{~km}$ beneath the western part of the volcano. The source region almost agrees with the path of the migrating Mogi source derived in this study.

Tanaka et al. (2000) obtained a three-dimensional velocity

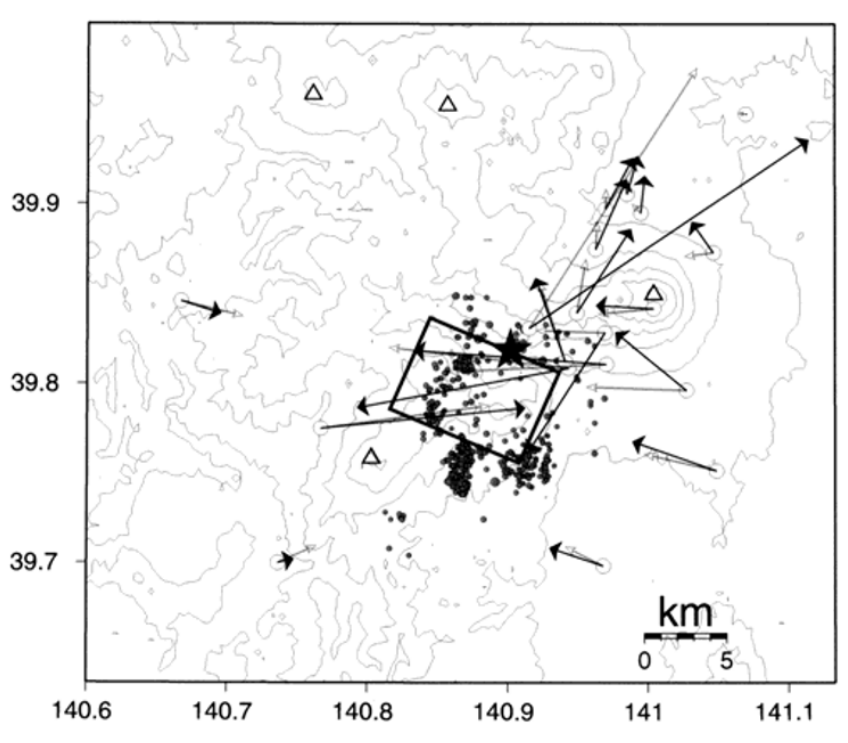

Fig. 8. Coseismic displacements associated with the M6.1 earthquake on September 3, 1998. A rectangle fault model was estimated from inversion analyses. Fault parameters are listed in Table 2. Black and white arrows indicate observed and calculated displacements, respectively. A rectangle, a closed star, and open triagles denote surface projection of the model fault, the epicenter of the earthquake, and active volcanoes, respectively.

structure at the shallow part of the volcano by means of $P$ and $S$ wave arrival times of natural earthquakes. They demonstrated the high $V_{P} / V_{S}(>2)$ region at 6-10 km west of the summit and 2-4 km in depth, which also coincides with the location of pressure sources in this study. These results from independent studies suggest that the existence of pressurized material in the source region.

The conclusion of this study are summarized as follows: 1) The notable crustal deformation was observed by our dense GPS network associated with the 1998 volcanic activity of Iwate volcano. 2) One of the possible source models started with a tensile fault at $5 \mathrm{~km}$ west of the summit and $3 \mathrm{~km}$ in depth in the beginning of the activity then changed its nature to an isotropic pressure source and migrated to westward. 3) A fault model of the M6.1 earthquake of September 3, 1998, which took place at about $10 \mathrm{~km} \mathrm{SW}$ of the summit, 
was proposed by means of the coseismic deformations. The fault parameters derived in this study show good agreement with the results from seismological studies. 4) After the earthquake, the volcanic deformation was decreased in rate.

Acknowledgments. We acknowledge Geographical Survey Institute of Japan forwarding their GPS data. We are grateful for the invaluable suggestions and discussions by Profs. T. Hirasawa, A. Hasegawa and all members at Research Center for Prediction of Earthquakes and Volcanic Eruptions, Graduate School of Science, Tohoku University. We also thank to Dr. T. Sagiya of Geographical Survey Institute of Japan for his willing consent in using program, FLTINV. We are much obliged to many organizations and people around the Iwate volcano who gave us opportunities to carry out the GPS observation. We are grateful to two reviewers, Prof. K. Ishihara and Dr. T. Imakiire, for their helpful comments and suggestions.

\section{References}

Geographical Survey Institute, Volcanic and seismic crustal deformations of Mt. Iwate detected by the JERS-1 synthetic aperture radar (SAR) interferometry, Rep. Coord. Commit. Earthq. Pred., 61, 86-90, 1999 (in Japanese).

Kimata, F., H. Mori, A. Suzuki, M. Sato, S. Ueki, H. Hamaguchi, H. Tsuji, A. Terada, E. Koyama, T. Takeda, H. Watanabe, R. Miyajima, M. Nakabo, T. Takayama, K. Yamamoto, K. Ishihara, K. Uchida, K. Matsushima, H. Yakiwara, and F. Hirano, Vertical crustal movement at the southern foot of Mount Iwate deduced by leveling survey, Chikyu, 21, 302-306, 1999 (in Japanese).

Koshiya, S., M. Oishi, M. Noda, Y. Okudera, T. Kato, S. Takiguchi, Y. Mitachi, M. Shimamori, T. Saito, K. Yanai, S. Hirano, H. Sawa, T. Fukudome, H. Sato, K. Otsuki, H. Nagahama, N. Nakamura, N. Doi, M. Togo, Y. Awata, and T. Yoshioka, Earthquake fault with the Iwate-ken Nairiku-hokubu earthquake of September 3, 1998, Active Fault Res., 17, 9-20, 1998 (in Japanese with an English abstract).

Matsu'ura, M. and Y. Hasegawa, A maximum likelihood approach to nonlinear inversion under constraints, Phys. Earth Planet. Inter., 47, 179-187, 1987.

Miyazaki, S., T. Saito, M. Sasaki, Y. Hatanaka, and Y. Iimura, Expansion of GSI's nationwide GPS array, Bull. Geogr. Surv. Inst., 43, 23-34, 1997.
Mogi, K., Relations between the eruptions of various volcanoes and the deformations of the ground surfaces around them, Bull. Earthquake Res. Inst. Tokyo, 36, 99-134, 1958.

National Space Development Agency of Japan and Nagoya University, Ground deformation activities detected by differential interferometric SAR using JERS-1/SAR around Iwate Volcano, Rep. Coord. Commit. Earthq. Pred., 61, 94-96, 1999 (in Japanese).

Nishimura, T., H. Nakamichi, S. Tanaka, M. Sato, T. Kobayashi, S. Ueki, H. Hamaguchi, M. Ohtake, and H. Sato, Source process of very long period seismic events associated with the 1998 activity of Iwate Volcano, northeastern Japan, J. Geophys. Res., 105, 19,135-19,148, 2000.

Okada, Y., Internal deformation due to shear and tensile faults in a halfspace, Bull. Seism. Soc. Am., 82, 1018-1040, 1992.

Saito, M., An automatic design algorithm for band selective recursive digital filters, Butsuri-Tanko (Geophys. Explor.), 31, 112-135, 1978 (in Japanese with an English abstract).

Sato, M. and H. Hamaguchi, Analysis of crustal deformation around Iwate volcano for the period from February to August, 1998, Chikyu, 21, 312317, 1999 (in Japanese).

Tanaka, S., H. Nakamichi, H. Hamaguchi, and S. Ueki, The 1998 seismic activity of Mount Iwate, Chikyu, 21, 273-279, 1999 (in Japanese).

Tanaka, S., H. Hamaguchi, S. Ueki, M. Sato, and H. Nakamichi, Migration of seismic activity during the 1998 volcanic unrest at Iwate volcano, northeastern Japan, with reference to $\mathrm{P}$ and $\mathrm{S}$ wave velocity anomaly and crustal deformation, J. Volcanol. Geotherm. Res., 2000 (in press).

Ueki, S., An attempt to identify the intruded material that caused the 1998 volcanic crisis of Iwate Volcano, EOS Trans. Amer. Geophys. U., 81(22), 234, 2000.

Ueki, S., Y. Morita, and H. Hamaguchi, On the volcanic tremor observed at Iwate Volcano in September and October, 1995, Tohoku J. Natural Disas. Sci., 32, 285-292, 1996 (in Japanese).

Ueki, S., S. Miura, T. Sato, K. Tachibana, and H. Hamaguchi, Crustal deformation around Iwate volcano, Chikyu, 21, 296-301, 1999 (in Japanese).

Umino, N., T. Okada, A. Nakamura, J. Nakajima, T. Sato, S. Hori, T. Kono, K. Nida, S. Ueki, T. Matsuzawa, A. Hasegawa, and H. Hamaguchi, Aftershock distribution for the M6.1 earthquake of 3 September 1998 in Shizukuishi, Iwate prefecture, northeastern Japan, Active Fault Res., 17 1-8, 1998 (in Japanese with an English abstract).

S. Miura (e-mail: miura@aob.geophys.tohoku.ac.jp), S. Ueki, T. Sato, K. Tachibana, and H. Hamaguchi 